JGG 2020;68:47-52

doi: $10.36150 / 2499-6564-375$

\title{
Atrial fibrillation: all the elderly go hospitalized? A minireview
}

\author{
Tiziana Ciarambino ${ }^{1}$, Gennaro Sansone ${ }^{2}$, \\ Ombretta Para ${ }^{3}$, Mauro Giordano² \\ ${ }^{1}$ Hospital of Marcianise, ASL Caserta, Italy; ${ }^{2}$ Department of Medical, Surgical, Neurological, \\ Metabolic, and Geriatric Sciences, University of Campania "L. Vanvitelli", Naples, Italy; ${ }^{3}$ Department \\ of Internal Medicine, Hospital of Careggi, University of Florence, Italy
}

Atrial fibrillation (AF) is a very common in clinical practice. The prevalence of $A F$ is high after the age of 65 years. Patients with $A F$ have a worse quality of life than healthy controls. However, concomitant higher hemorrhagic risks, severe cognitive and functional impairment may at least partly explain under-prescription of oral anticoagulants in the elderly.

Received: August 2, 2019

Accepted: January 7, 2020

\section{Correspondence}

Tiziana Ciarambino

Hospital of Marcianise,

ASL Caserta, via Orto dell'Abate, 81025

Marcianise (CE), Italy

E-mail: tiziana.ciarambino@gmail.com

\section{Conflict of interest}

The Authors declare no conflict of interest

How to cite this article: Ciarambino T, Sansone G, Para O, et al. Atrial fibrillation: all the elderly go hospitalized? A minireview. Journal of Gerontology and Geriatrics 2020;68:47-52. https://doi. org/10.36150/2499-6564-375

(C) Copyright by Società Italiana di Gerontologia e Geriatria (SIGG)

\section{(c) (i) $(9)$}

\section{OPEN ACCESS}

This is an open access article distributed in accordance with the CC-BY-NC-ND (Creative Commons Attribution-NonCommercial-NoDerivatives 4.0 International) license. The article can be used by giving appropriate credit and mentioning the license, but only for non-commercial purposes and only in the original version. For further information: https://creativecommons.org/licenses/by-nc-nd/4.0/deed.en

\section{EPIDEMIOLOGY}

Patients with Atrial fibrillation (AF) are at greater risk for thromboembolic events, hospitalization, heart failure and death ${ }^{1-3}$. Clinical risk factors for $A F$ are reported in Table I. The prevalence of AF is high after the age of 65 years and it is 1.5 times more frequent in men than women ${ }^{4-5}$. For example, the prevalence rate in males 75-79 aged is doubled compared to males aged 65-69 years and more than 5 times greater than males 55-59 years old ${ }^{6}$. However, in the European Union by 2030, about 120.000-215.000 newly diagnosed patients per year are estimated ${ }^{7}$.

\section{TYPES}

Traditionally there are five types of Atrial fibrillation ${ }^{7}$ :

- first diagnosed atrial fibrillation. Atrial fibrillation that has not yet been diagnosed, not taking into account the duration of the arrhythmia, the presence and severity of symptoms;

- paroxysmal atrial fibrillation. Atrial fibrillation ends spontaneously in the first 48 hours in most cases. Some AF can last up to 7 days. An episode of AF with a cardioversion within seven days should still be considered paroxysmal;

Table I. Clinical risk factors for atrial fibrillation.

\begin{tabular}{|l|}
\hline Advanced age \\
\hline Diabetes \\
\hline Hypertension \\
\hline Congestive heart failure \\
\hline Rheumatic and non-rheumatic valvular disease \\
\hline Myocardial infarction \\
\hline
\end{tabular}


- persistent atrial fibrillation. Atrial fibrillation that lasts more than 7 days. Also episodes where there is a cardioversion with both drugs and dc-shock after 7 days or more;

- long-standing persistent atrial fibrillation. Continuous AF that lasts for $\geq 1$ year when you decide to use rhythm control;

- permanent atrial fibrillation. Atrial fibrillation that is accepted by the patient (and physician).

\section{SIGNS AND SYMPTOMS}

Patients with AF have a worse quality of life than healthy controls. They develop a range of symptoms ranging from lethargy, palpitations, dyspnea, chest pain, difficulty sleeping and psychosocial distress. In Emergency department it's not uncommon to find patients with signs of congestive heart failure (as pulmonary edema, peripheral edema, ascites) or with signs of embolism (ischemic attack transient, or stroke) ${ }^{7}$.

\section{MANAGEMENT}

In the Emergency Department in the evaluation of AF play a fundamental role, a history and physical examination, specific laboratory and cardiological tests.

\section{HISTORY AND PHYSICAL EXAMINATION}

Not all patients with AF are symptomatic, so the history and physical examination must focus on a few key points ${ }^{8}$ :

- description of symptoms, focusing on the severity and qualitative characteristics of the symptoms;

- possible precipitating causes;

- the presence of associated pathologies such as, cardiovascular or cerebrovascular diseases, diabetes, hypertension, chronic obstructive pulmonary disease, obstructive sleep apnea syndrome, alcohol and hyperthyroidism, which can be potentially reversible, causes;

- cardiopulmonary and neurological examination is essential because they can highlight the presence of complications such as congestive heart failure or stroke.

\section{EKG}

The electrocardiogram, (EKG), (class IB) is necessary to make the diagnosis. AF has the following electrocardiographic characteristics ${ }^{7}$ :

- the RR intervals follow no repetitive pattern;

- there are no distinct $P$ waves.

\section{ECHOCARDIOGRAPHY}

A transthoracic echocardiography (classed IC) is another crucial exam to do because it is important to know:

- the size of the atria. In fact, large atria could orient to a long-term AF and lean towards a more conservative therapeutic strategy;

- structural anomalies. In particular, it can guide vs the use of rhythm control drugs (as amiodarone) rather than others (as flecainide and propafenone).

Certainly transthoracic echocardiography has a very low sensitivity to recognize the presence of atrial thrombi. In this case it is necessary to carry out a trans esophageal echocardiography ${ }^{7-8}$.

\section{BASELINE LABORATORY TESTING}

Baseline tests test include ${ }^{7}$ :

- thyroid evaluation. In particular, hyperthyroidism is present in less than $5 \%$ of patients with AF. Generally we should have in all the patients with AF a TSH and free T4 (9-10);

- complete blood count;

- serum creatinine;

- analysis for proteinuria;

- test for diabetes mellitus;

- test to study possible risk factors and concomitant diseases.

\section{CLUSTER DISEASE}

Hypertension and coronary heart disease are the most common diseases found in patients with $A F$ in developed countries. The rheumatic disease, still very present in developing countries, is very much associated with the incidence of AF. Cluster diseases associated to AF are reported in Table II.

\section{HYPERTENSIVE DISEASE}

Hypertension is the most common disorder present in patients with AF. Also due to the high frequency of hypertension in the general population, the history of hypertension increased the risk of developing AF about 1.42 fold ${ }^{11}$.

Table II. Cluster Diseases associated to atrial fibrillation.

\begin{tabular}{|l|}
\hline Hypertensive disease \\
\hline Coronary disease \\
\hline Valvular heart disease \\
\hline Heart failure (HF) \\
\hline Venous thromboembolic disease \\
\hline Chronic obstructive pulmonary disease \\
\hline Obstructive sleep apnea syndrome \\
\hline Obesity \\
\hline Diabetes \\
\hline Chronic kidney disease \\
\hline
\end{tabular}




\section{Coronary disease}

Atrial fibrillation occurs in 6-10\% of patients with acute myocardial infarction. These patients also have a poorer prognosis, and have a mortality increase at 30 days and 1 year ${ }^{12}$.

\section{VALVULAR HEART DISEASE}

Almost any valvular lesion that leads to significant stenosis or regurgitation is associated with the development of AF. In a review of 89 patients with mitral valve prolapse and 360 with flail leaflets, the rate of development of $\mathrm{AF}$ was about $5 \%$ per year ${ }^{13}$. Atrial fibrillation is an infrequent (about 1\%) in patients with aortic valvular diseases. Left atria and age are the most important parameters to determine the occurrence of $A F$ in patients with rheumatic heart disease ${ }^{13,14}$.

\section{Heart failure (HF)}

Atrial fibrillation and heart failure (HF) often occur together and each of the two can predispose to the other. Atrial fibrillation is found in more than one half of individuals with HF. These data are particularly interesting, because knowing that one third of people with AF can develop Heart Failure; it's possible to start a prevention of HF and prevention of stroke ${ }^{15}$

\section{Venous thromboembolic diseASE}

The risk of Atrial fibrillation is increased in patients with Deep Vein Thromboembolism or Pulmonary thromboembolism. The mechanism is not known, but is probably due to the increase in pulmonary vascular resistance and to the right post cardiac loading that cause a right atrial strain. Pulmonary thromboembolism is more frequently associated with AF than Deep Vein Thromboembolism ${ }^{16}$.

\section{Chronic obstructive pulmonary disease}

In patients with chronic obstructive pulmonary disease it has been shown that the reduction of $\mathrm{FEV}_{1}$ correlates with an increase in the incidence of $A F^{17}$.

\section{OBSTRUCTIVE SLEEP APNEA SYNDROME}

There is a possible causal relationship between obstructive sleep apnea syndrome (OSAS) and AF. A history of hypoxemia and hypercapnia may lead to an increase in circulating catecholamine that may predispose to AF. In addition, the presence of numerous increased inflammation factors in patients with OSAS may predispose to $A F^{18}$.

\section{OBesity}

Obese individuals (as body mass index [BMl] $>30 \mathrm{~kg} /$ $\mathrm{m}^{2}$ ) are significantly more likely to develop AF than those with a normal BMI $\left(<25 \mathrm{~kg} / \mathrm{m}^{2}\right)$. In the Framingham Heart Study, every unit increase in BMl was associated with about $5 \%$ an increase in risk ${ }^{19}$.

\section{DiABetes}

In the Framingham Heart Study (over 4700 individuals without valvular heart disease), the presence of diabetes was associated with a significantly increased risk for the development of $\mathrm{AF}^{20}$.

\section{Chronic KIDNEY DISEASE}

Chronic kidney disease (CKD) increases the risk of the development of AF. In patients with CKD there are several reasons to develop AF. They tend to have higher pression values and an overload of fluids that can lead to ventricular hypertrophy, atrial stretch, and fibrosis. In addition CKD patients have an up-regulated renin-angiotensin-aldosteron (RAA) system that can cause remodeling of the heart chambers and predispose to $\mathrm{AF}^{21}$.

\section{TREATMENT}

A key point for the management of $A F$ for the healthcare providers is to know if is new or old onset AF.

\section{RATE VS RHYTHM CONTROL}

Rate control is indicated in hemodynamically stable patients with AF more than 48 hours, in which immediate cardioversion cannot be performed. The rationale for rate control is to avoid hemodynamic instability, improve symptoms and avoid tachycardia-mediated cardiomyopathy. There are two frequency targets ${ }^{22}$ :

- $<80$ beats/min at rest and $<110$ beats/min under stress;

- $<110$ beats/min.

It is not clear what the best strategy is, but above all in the initial phases, more delicate management can be accepted ${ }^{7}$. In the presence of structural heart disease, it is recommended amiodarone (loading dose: $5-7 \mathrm{mg} / \mathrm{kg}$ over 1-2 hours; and follow-up dose $50 \mathrm{mg} /$ hour to maximum of $1.0 \mathrm{~g}$ over 24 hours). Amiodarone has an efficacy comparable to the drugs of the class Ic (as flecainide, $1.5-2 \mathrm{mg} / \mathrm{kg}$ over $10 \mathrm{~min}$ iv or propafenone, $1.5-2 \mathrm{mg} /$ $\mathrm{kg}$ over $10 \mathrm{~min}$ ) in the return to sinus rhythm in the first 24 hours. The drugs of the class lc show a more rapid onset of action, with some effects already after 1-2 hours after administration ${ }^{24,25}$. It is crucial avoid these drugs (class Ic) in the presence of structural heart diseases.

Rhythm control can be obtained with two methods:

- pharmacological or electrical cardioversion.

\section{Pharmacological cardioversion}

The drugs used in the rhythm control (class IB) are reported in Table III. A disadvantage of pharmacological cardioversion is that the patient must be observed for at least 50\% of the half-life, so as to check the pro-arrhythmic effects of these drugs ${ }^{7,23}$. 
Table III. The drugs used in the rhythm control (class IB).

\begin{tabular}{|c|}
\hline $\begin{array}{l}\text { Beta blockers } \\
\text { - Metoprolol ( } 2.5-10 \mathrm{mg} \text { intravenous bolus, repeated as required) } \\
\text { - Esmololo ( } 0.5 \mathrm{mg} / \mathrm{kg} \text { intravenous bolus over } 1 \mathrm{~min} \text {; then } 0.05 \text { - } \\
0.25 \mathrm{mg} / \mathrm{kg} / \mathrm{min})\end{array}$ \\
\hline $\begin{array}{l}\text { Calcium channel blockers } \\
\text { - Verapamil (2.5-10 mg intravenous bolus) } \\
\text { or } \\
\text { - Diltiazem (15-25 mg intravenous bolus) } \\
\text { (both repeated as required) } \\
\end{array}$ \\
\hline $\begin{array}{l}\text { Digoxin } \\
0.5 \mathrm{mg} \text { intravenous bolus and after } 0.75-1.5 \mathrm{mg} \text { over } 24 \text { hours in } \\
\text { divided doses }\end{array}$ \\
\hline
\end{tabular}

The management of the AF with rhythm control offers no advantages compared to the rate control or rather can be aggravated by numerous side effects ${ }^{26}$.

\section{ELECTRICAL CARDIOVERSION}

In hemodynamically unstable patients, an emergency electrical cardioversion is indicated ${ }^{7}$. It has a success rate ranging from $67-94 \%$, remains a very safe technique and the most effective in ending AF. It is necessary to obtain sedation analgesia with drugs, such as Fentanyl, Midazolam, or Propofol. The risks of this procedure are related to sedation, as skin burns and pro-arrhythmias, which are very rare since the shock is synchronized with the $Q R S^{23}$.

\section{PREVENTION OF EMBOLIZATION}

Various trials and meta-analyzes have shown how the use of an antithrombotic therapy reduces the onset of stroke ${ }^{26-28}$. For the choice to make or not an anticoagulant therapy it is necessary to be guided by the $\mathrm{CHA}_{2} \mathrm{DS}_{2}$ VASc score. In particular, oral anticoagulation therapy to prevent thromboembolism is recommended for all male AF patients with a CHADS-VASc score of 2 or more, and of 3 or more for all female with AF (class IA).

The drugs of choice are:

- warfarin;

- direct thrombin inhibitors as dabigatran;

- inhibitors of factor Xa (as rivaroxaban, apixaban, edoxaban);

The oral anticoagulant (NOACs) seem to have better clinical benefits and a better safety profile with regard to bleeding, than warfarin, in particularly in the elderly and the frailty elderly ${ }^{7,28-34}$. Although the use of NOACs is associated with a reduction in bleeding, about $2.1-3.6 \%$ of major bleeding is found ${ }^{35}$. To this regard, two specific antidotes were approved by the FDA, as idarucizumab for dabigatran, and alpha-andexanet for apixaban e rivaroxaban ${ }^{36}$. In addition, non-specific prohaemostatic agents have also been used, as prothrombin complex concentrate (PCC) and activated prothrombin complex concentrate (APCC). For the management of life-threatening bleeding or bleeding in critical organs, or major bleeding that do not respond to supportive therapies, it is recommended to use antidotes or nonspecific prohemostatic agents, while in other bleeding is not recommended. In fact in other bleeding are recommended:

- withdrawal of NOACs and other drugs that interfere with coagulation (as antiplatelet);

- direct compression of the bleeding site;

- volume resuscitation and transfusion.

For patients with mucosal bleeding (epistaxis and uterine bleeding) anti-fibrinolytic therapy is recommended. In cases of suspected overdose, oral activated charcoal may be useful to reduce absorption if it occurred in the last hours ${ }^{36}$.

\section{NOACS IN ELDERLY}

Female patients with AF are older, with more frequent cognitive and functional impairment, and higher rate of comorbidity than males ${ }^{37,38}$. The risk of stroke is known to increase with increasing age ${ }^{39}$. Aspirin is still used in patients over 75 years of age, because considered more convenient. Numerous trials (as BAFTA trial and AVERROES trial) demonstrated how warfarin and NOACs are more effective and safety than aspirin ${ }^{40,41}$. In patients over 90 years of age, warfarin and NOACs are more effective in reducing stroke, and NOACs are more effective in reducing intracranial hemorrhage $(\mathrm{ICH})$ than warfarin ${ }^{42}$. The best drugs for the prevention of embolization in elderly patients remain the NOACs, even if only $16.1 \%$ of very elderly population receives the NOACs ${ }^{42}$.

\section{PREVENTION OF EMBOLIZATION IN CKD}

Numerous studies have been carried out on patients with $\mathrm{CKD}$ and $\mathrm{AF}$, especially regarding the issue of prevention of embolization. CKD alone is a risk factor for stroke and prothrombotic states. In moderate CKD, is recommended both warfarin and reduced dose of NOACs (as reported in Table M). In the case of end stage renal disease and hemodialysis patients there are no very decisive studies. The NOACs have a greater renal metabolism compared to warfarin. In particular, dabigatran almost completely metabolized via the kidney (80\%) and apixaban instead only a small part (25\%). The FDA authorized the use of apixaban and rivaroxaban in these patients. The AHA ACC/ HRS recommended warfarin in this type of patients even if numerous studies are still necessary ${ }^{43}$. In patients with chronic kidney disease, the use of low molecular weight heparin (LMWH), as enoxaparin, remains quite safe, even 
Table IV. The NOACs in patients with CKD moderate.

\begin{tabular}{|l|}
\hline Dabigatran (110 $\mathrm{mg}$ bis in die) \\
\hline Apixaban (2.5 $\mathrm{mg}$ bis in die) \\
\hline Rivarxaban (15 $\mathrm{mg}$ once daily) \\
\hline Edoxaban (30 $\mathrm{mg}$ once daily) \\
\hline
\end{tabular}

in those patients with glomerular filtration rate below $30 \mathrm{ml} /$ $\mathrm{min} / 1.73 \mathrm{~m}^{2}$, with a dosage of $1 \mathrm{mg} / \mathrm{kg}$ once daily ${ }^{44}$.

\section{INDICATIONS FOR HOSPITALIZATION}

Most of the new-onset AF agents are not hospitalized. Possible indications for hospitalization of patients with new-onset AF are reported ${ }^{45}$ :

- patients considering ablation. Especially if very symptomatic associated with elevated ventricular response or haemodynamically unstable;

- patients with severe bradycardia post cardioversion;

- treatment of other concomitant pathologies of AF (as exacerbation of chronic obstructive pulmonary disease, thyrotoxicosis, infections, pulmonary embolism, coronary syndrome);

- treatment of elderly patients. In fact, in these patients embolic events are more easily found and very often have numerous comorbidities ${ }^{46}$;

- start of a chronic rhythm control therapy;

- management of heart failure and hypertension after control of the rhythm or the control rate.

\section{CONCLUSIONS}

Prevention of thromboembolic risk in elderly with AF is an imperative clinical need. However, concomitant higher hemorrhagic risk and other characteristics that were more frequent in elderly patients (as severe cognitive, CKD, comorbidity and functional impairment) may at least partly explain the under-prescription of oral anticoagulants in these patients.

\section{References}

1 Chugh SS, Blackshear JL, Shen WK, et al. Epidemiology and natural history of atrial fibrillation: clinical implications. J Am Coll Cardiol 2001;37:371. https://doi.org/10.1016/s07351097(00)01107-4

2 Testa G, Cacciatore F, Della-Morte D, et al. Role of permanent atrial fibrillation (AF) on long-term mortality in communitydwelling elderly people with and without chronic heart failure (CHF). Arch Gerontol Geriatr 2012;55:91-5. https://doi. org/10.1016/j.archger.2011.06.003.

3 Campobasso CP, Bugelli V, De Micco F, et al. Suddent cardiac death in elderly: the post-mortem examination of senile myocardium and myocardial infarction. Journal of Gerontology and Geriatrics 2017;65:223-31.

4 Benjamin EJ, WolfPA, D'Agostino RB, et al. Impact of atrial fibrillation on the risk of death: the Framingham Heart study. Circulation 1998;98:946. https://doi.org/10.1161/01.cir.98.10.946

5 Kannel WB, Abbott RD, Savage DD. Epidemiologic features of chronic atrial fibrillation: the Framingham study. $\mathrm{N}$ Engl J Med 1982;306:1018-22. https://doi.org/10.1056/ NEJM198204293061703

6 Ball J, Carrington MJ, McMurray $\mathrm{JJ}$, et al. Atrial fibrillation: profile and burden of an evolving epidemic in the $21^{\text {st }}$ century. Int J Cardiol 2013;167:1807. https://doi.org/10.1161/CIRCULATIONAHA.113.005119

7 Chugh SS, Havmoeller R, Narayanan K, et al. Worldwide epidemiology of atrial fibrillation: a Global Burden of Disease 2010 study. Circulation 2014;129:837. https://doi. org/10.1161/CIRCULATIONAHA.113.005119

8 Kirchhof P, Benussi S, Kotecha D, et al. 2016 ESC Guidelines for the management of atrial fibrillation developed in collaboration with EACTS. Eur Heart J 2016;37:2893-962. https:// doi.org/10.1093/ejcts/ezw313

9 Kumar K, Zimetbaum PJ, Saperia GM. Overview of atrial fibrillation. Up to date 04/2019.

10 Krahn AD, Klein GJ, Kerr CR. How useful is thyroid function testing in patients with recent-onset atrial fibrillation? The $\mathrm{Ca}$ nadian Registry of Atrial Fibrillation Investigators. Arch Intern Med 1996;156:2221.

11 Krahn AD, Manfreda J, Tate RB. The natural history of atrial fibrillation: incidence, risk factors, and prognosis in the Manitoba follow-up study. Am J Med 1995;98:476. https://doi. org/10.1016/S0002-9343(99)80348-9

12 Wong CK, White HD, Wilcox RG. New atrial fibrillation after acute myocardial infarction independently predicts death: the GUSTO-III experience. Am Heart J 2000;140:878-85. https://doi.org/10.1067/mhj.2000.111108

13 Grigioni F, Avierinos JF, Ling LH. Atrial fibrillation complicating the course of degenerative mitral regurgitation: determinants and long-term outcome. J Am Coll Cardiol 2002;40:84-92. https://doi.org/10.1016/s0735-1097(02)01922-8

14 Diker E, Aydogdu S, Ozdemir M, Prevalence and predictors of atrial fibrillation in rheumatic valvular heart disease. Am J Cardiol 1996;77:96. https://doi.org/10.1016/s0002-9149(97)89145-x

15 Santhanakrishnan R, Wang N, Larson MG, Atrial fibrillation begets heart failure and vice versa: temporal associations and differences in preserved versus reduced ejection fraction. Circulation 2016;133:484-92. https:doi.org/10.1161/CIRCULATIONAHA. 115.018614

16 Hald EM, Enga KF, Løchen ML. Venous thromboembolism increases the risk of atrial fibrillation: the Tromso study. J Am Heart Assoc 2014;3:e000483. https:doi.org/10.1161/ JAHA. 113.000483

17 Buch P, Friberg J, Scharling H. Reduced lung function and risk of atrial fibrillation in the Copenhagen City Heart study. Eur Respir J 2003;21:1012. https:doi.org/10.1183/09031936.03.00051502

18 Gami AS, Pressman G, Caples SM. Association of atrial fibrillation and obstructive sleep apnea. 
Circulation 2004;110:364;110:364-7. https:doi.org/10.1161/01. CIR.0000136587.68725.8E

19 Wang TJ, Parise H, Levy D. Obesity and the risk of newonset atrial fibrillation. JAMA 2004;292:2471. https:doi. org/10.1001/jama.292.20.2471

20 Benjamin EJ, Levy D, Vaziri SM. Independent risk factors for atrial fibrillation in a population-based cohort. The Framingham Heart study. JAMA 1994;271:840.

21 Alonso A, Lopez FL, Matsushita K. Chronic kidney disease is associated with the incidence of atrial fibrillation: the Atherosclerosis Risk in Communities (ARIC) study. Circulation 2011;123:2946. https://doi.org/10.1161/CIRCULATIONAHA.111.020982

22 Dorian P. Rate control in atrial fibrillation. N Engl J Med 2010;362:1439. https://doi.org/10.1056/NEJMe1002301

23 Naccarelli GV, Dell'Orfano JT, Wolbrette DL, et al. Cost-effective management of acute atrial fibrillation: role of rate control, spontaneous conversion, medical and direct current cardioversion, transesophageal echocardiography, and antiembolic therapy. Am J Cardiol 2000;85:36D. https://doi.org/10.1016/ s0002-9149(00)00905-x

24 Naccarelli GV, Ganz LI, Manning WJ. Atrial fibrillation: cardioversion to sinus rhythm, Up to date 02/2019.

25 Chevalier P, Durand-Dubief A, Burri H, et al. Amiodarone versus placeboand class lc drugs for cardioversion of recent-onsetatrial fibrillation: a meta-analysis. J Am Coll Cardiol 2003;41:255.67. https://doi.org/10.1016/s0735-1097(02)02705-5. https://doi. org/10.1016/s0735-1097(02)02705-5

26 Corbi G, Gambassi G, Pagano G, et al. Impact of an innovative educational strategy on medication appropriate use and length of stay in elderly patients. Medicine (Baltimore). 2015;94:e918. https://doi.org/10.1097/MD.0000000000000918

27 Wyse DG, Waldo AL, DiMarco JP, et al. A comparison of rate control and rhythm control in patients with atrial fibrillation. $\mathrm{N}$ Engl J Med 2002;347:1825. https://doi.org/10.1056/NEJMoa021328

28 Risk factors for stroke and efficacy of antithrombotic therapy in atrial fibrillation. Analysis of pooled data from five randomized controlled trials. Arch Intern Med 1994;154:1449.

29 Hart RG, Pearce LA, Aguilar MI. Meta-analysis: antithrombotic therapy to prevent stroke in patients who have nonvalvular atrial fibrillation. Ann Intern Med 2007;146:857. https://doi. org/10.7326/0003-4819-146-12-200706190-00007

30 Lip GY, Skjøth F, Rasmussen LH, et al. Oral anticoagulation, aspirin, or no therapy in patients with nonvalvular AF with 0 or 1 stroke risk factor based on the CHA2DS2-VASc score. J Am Coll Cardiol 2015;65:1385. https://doi.org/10.1016/j. jacc.2015.01.044

31 Banerjee A, Lane DA, Torp-Pedersen C, et al. Net clinical benefit of new oral anticoagulants (dabigatran, rivaroxaban, apixaban) versus no treatment in a 'real world' atrial fibrillation population: a modelling analysis based on a nationwide cohort study. Thromb Haemost 2012;107:584. https://doi. org/10.1160/TH11-11-0784

32 Connolly SJ, Ezekowitz MD, Yusuf S, et al. Dabigatran versus warfarin in patients with atrial fibrillation. N Engl J Med 2009;361:1139. https://doi.org/10.1056/NEJMoa0905561

з3 Patel MR, Mahaffey KW, Garg J, et al. Rivaroxaban versus warfarin in nonvalvular atrial fibrillation. N Engl J Med 2011;365:883. https://doi.org/10.1056/NEJMoa1009638

34 Granger CB, Alexander JH, McMurray JJ, et al. Apixaban versus warfarin in patients with atrial fibrillation. N Engl J Med 2011;365:981. https://doi.org/10.1056/NEJMoa1107039

35 Olesen JB, Lip GY, Lindhardsen J, et al. Risks of thromboembolism and bleeding with thromboprophylaxis in patients with atrial fibrillation: a net clinical benefit analysis using a 'real world' Nationwide Cohort study. Thromb Haemost 2011;106:739. https://doi.org/10.1160/TH11-05-0364

36 Cuker A, Burnett A, Triller D. Reversal of direct oral anticoagulants: guidance from the Anticoagulation forum. Am J Hematol 201994:697-709. https://doi.org/10.1002/ajh.25475

37 Politi C, Ciarambino T, Riva L, et al.; on behalf of ATA-AF Steering Committee and Investigators. Sex-gender and atrial fibrillation treatment in the AntiThrombotic Agents in Atrial Fibrillation (ATA-AF) study. It J Med 2016;10. https://doi. org/10.4081/itjm.2016.649

38 Ciarambino T, Corbi M, Filippelli A, et al. Anticoagulant drugs and gender: what is in the elderly? A minireview. Journal of Gerontology and Geriatrics 2019;67:123-6.

39 Para O, Caruso L, Bacci F, et al. Risk factors and outcomes of new-onset atrial fibrillation in patients hospitalized in an internal medicine ward: a case-control study. Intern Emerg Med 2019 Jul 13. https://doi.org/10.1007/s11739-01902151-y [Epub ahead of print]

40 Mant J, Hobbs FD, Fletcher K, et al. BAFTA Investigators; Midland Research Practices Network (MidReC). Warfarin versus aspirin for stroke prevention in an elderly community population with atrial fibrillation (the Birmingham Atrial Fibrillation Treatment of the Aged study, BAFTA): a randomised controlled trial. Lancet 2007;370:493-503. https://doi. org/10.1016/S0140-6736(07)61233-1

$41 \mathrm{Ng} \mathrm{KH}$, Shestakovska O, Connolly SJ, et al. Efficacy and safety of apixaban compared with aspirin in the elderly: a subgroup analysis from the AVERROES trial. Age Ageing 2016;45:77-83. https://doi.org/10.1093/ageing/afv156

42 Chao TF, Liu CJ, Lin YJ. Oral Anticoagulation in very elderly patients with atrial fibrillation: a Nationwide Cohort study. Circulation 2018;138:37-47. https://doi.org/10.1161/CIRCULATIONAHA.117.031658

43 Zhang L, Steckman DA, Adelstein EC. Oral anticoagulation for atrial fibrillation thromboembolism prophylaxis in the chronic kidney disease population: the state of the art in 2019. Cardiovasc Drugs Ther 2019;33:481-8. https://doi.org/10.1007/ s10557-019-06885-x

44 Saheb Sharif-Askari F, Syed Sulaiman SA, Saheb SharifAskari N. Anticoagulation therapy in patients with chronic kidney disease. Adv Exp Med Biol 2017;906:101-14. https:// doi.org/10.1007/5584_2016_109

45 Phang R, Olshansky B, Zimetbaum PJ. New onset atrial fibrillation. Up to date 25/03/2019.

46 Bencivenga L, Komici K, Corbi G, et al. The management of combined antithrombotic therapy in patients with atrial fibrillation undergoing percutaneous coronary intervention: a particularly complex challenge, especially in the elderly. Front Physiol 2018;9:876. https://doi.org/10.3389/fphys.2018.00876 